\title{
Desenvolvimento Local \\ Perspectivas Socioculturais e Históricas Sobre uma Cidade do Sul de Minas Gerais
}

http://dx.doi.org/10.21527/2237-6453.2019.49.79-93

Recebido em: $12 / 11 / 2017$

Aceito em: 3/6/2019

\section{Silas Dorival de Oliveira ${ }^{1}$, Carlos Alberto Máximo Pimenta ${ }^{2}$}

\begin{abstract}
RESUMO
Trata-se de um estudo sobre desenvolvimento local em suas dimensões socioculturais e históricas, inscritas em uma cidade do sul de Minas Gerais, no qual se utiliza de conhecimentos da antropologia, história e sociologia. Objetiva-se identificar os elementos inscritos em uma determinada sociedade que revelam dimensões socioculturais determinantes para o desenvolvimento local. Justifica-se pela necessidade de pesquisas sobre a mesorregião sul de Minas Gerais, suas diferentes realidades e formatações de desenvolvimento. Do ponto de vista metodológico, realizou-se análise de documentos históricos, observação de campo e entrevistas dialogais. As concepções teóricas são postas em conjunto com os dados empíricos, e indicam elementos políticos, culturais, econômicos e geográficos que organizam o imaginário sobre o processo de desenvolvimento.
\end{abstract}

Palavras-chave: Desenvolvimento local. Sul de Minas Gerais. Dimensões socioculturais e históricas.

\section{LOCAL DEVELOPMENT: \\ SOCIOCULTURAL AND HISTORICAL PERSPECTIVES ABOUT A CITY IN THE SOUTH OF MINAS GERAIS}

\section{ABTRACT}

This paper presents study about local development in its socio-cultural and historical dimensions, inscribed in a city in the south of Minas Gerais, in which anthropological, historical and social knowledge are used. The objective is to identify the elements registered in a given society that reveals socio-cultural dimensions that are decisive for local development. It is justified by the need for research on the southern mesoregion of Minas Gerais, its different realities and development formats. From the methodological point of view, analysis of historical documents, field observation and dialogues interviews were carried out. The theoretical conceptions are put together with the empirical data, and we indicate political, cultural, economic and geographical elements that organize the imaginary about the development process.

Keywords: Local development. South of Minas Gerias. Socio-cultural and historical dimensions.

\footnotetext{
${ }^{1}$ Mestre em Desenvolvimento, Tecnologias e Sociedade pela Universidade Federal de Itajubá (Unifei). Professor de Filosofia e Sociologia da Fundação Bradesco Itajubá MG. silas0686@gmail.com

${ }^{2}$ Doutor em Ciências Sociais pela Pontifícia Universidade Católica de São Paulo (PUC-SP). Professor da Universidade Federal de Itajubá (Unifei). carlospimenta@unifei.edu.br
} 
Este artigo tratou das questões do desenvolvimento local, levando-se em consideração as suas dimensões socioculturais e históricas, as quais conferiram amplitude ao termo e permitiram aprofundamentos à compreensão do tema proposto.

Trata-se de desdobramentos de pesquisas executadas no Programa de Pós-Graduação em Desenvolvimento, Tecnologias e Sociedade (PPG DTecS) da Universidade Federal de Itajubá (Unifei), estas vinculadas aos projetos (a) Indicativos do Desenvolvimento no Município de Itajubá, MG: Investimentos Públicos e Privados, e (b) Observatório de Desenvolvimento e Cultura, no Sul do Estado de Minas Gerais. ${ }^{3}$

A proposta do estudo delimita-se à cidade de Itajubá, localizada no Sul de Minas Gerais, por ser local de configurações específicas que conferem a possibilidade de reflexões significativas sobre o processo de desenvolvimento vivenciado nesta localidade.

$O$ referido esforço justifica-se pela necessidade de pesquisas sobre a mesorregião Sul de Minas Gerais, suas diferentes realidades e formatações de desenvolvimento. Como rebatimento, vislumbra-se, também, a possibilidade de subsidiar políticas de desenvolvimento com os dados e informações levantados nesta pesquisa.

A pergunta que norteou este estudo é a seguinte: Quais elementos socioculturais, políticos e geográficos compõem a concepção de desenvolvimento presente na cidade de Itajubá, MG? A resposta para a pergunta formulada requer superar verdades disciplinares, e esta superação, por olhares que ultrapassem as noções de crescimento econômico.

Diante dessas considerações de partida, tem-se por objetivo identificar elementos socioculturais, políticos e geográficos que compõem a concepção de desenvolvimento de Itajubá, MG, e o que são determinantes para a compreensão do desenvolvimento local como superação das demandas sociais contemporâneas.

Por esta razão, tem-se apostado na análise interdisciplinar, uma vez que o objeto estudado pressupõe olhares em diferentes campos do conhecimento e, do ponto de vista metodológico, no que se refere aos instrumentos de coleta de dados, ressalta-se que o levantamento contou com o uso de técnicas da antropologia para efetivação das entrevistas dialogais e observação de campo e da história, referentes à escolha e análise de documentos.

No que diz respeito à análise dos dados levantados, pautou-se por privilegiar as informações extraídas de um grupo de pessoas e entrevistados para se compreender os processos de representação e de imaginação hegemônicos no coletivo e na organização social, sem perder de horizonte seus rebatimentos às questões geográficas, econômicas e de políticas públicas.

Os dados coletados em campo foram confrontados com informações presentes na história oficial de Itajubá. Para a sistematização dos dados, resultantes do confronto proposto, foi necessário lançar mão de dois critérios instrumentais:

a) análise minuciosa de documentos históricos e jornais impressos, disponíveis em Itajubá, datados dos anos 30 em diante, levando-se em consideração a óptica do paradigma indiciário (GINZBURG, 1989).

${ }^{3}$ Os projetos citados foram financiados pela Fundação de Amparo à Pesquisa do Estado de Minas Gerais (Fapemig). 
Os documentos foram extraídos de Decretos, Atas e Comunicações oriundas da Câmara Municipal e da Prefeitura. Em outros termos, os critérios de escolha dos documentos circunscrevem-se aos resultados das discussões promovidas na Câmara Municipal, bem como dos debates e posições divulgados nos jornais, especificamente aqueles que apontam caminhos de organização do município (urbanização, organização social, econômica, política e religiosa, etc.).

b) entrevistas dialogais com indivíduos que possuem ligação com a ideia de desenvolvimento da microrregião. A escolha dos entrevistados se deu pelos indicativos dos documentos oficiais que, em suas entrelinhas, indicam indivíduos que estiveram à margem do sistema produtivo. Foram entrevistadas 9 pessoas, todas com idade superior a 75 anos. Neste esforço de síntese, utilizou-se dos fragmentos das falas, as quais expressaram as pretensões exaradas no texto.

É importante deixar consignado para a caracterização dos argumentos que sustentam o texto, que dois pontos de partida justificam a relação entre documentos históricos, imaginário social e desenvolvimento em suas dimensões socioculturais, sendo eles: (1) o período temporal dos dados utilizados; (2) os critérios de escolhas dos documentos oficiais e dos entrevistados.

A determinação do período da pesquisa, da década de 30 para 2018, não ocorreu de maneira aleatória. Toma-se como elemento de justificativa a leitura de lanni (1992), no livro "A Ideia de Brasil Moderno", em que aponta o começo da inserção do Brasil à lógica da modernidade. Esses rebatimentos políticos, econômicos, filosóficos e socioculturais, aos poucos, começam a difundir suas bases na construção de um pensamento nacional sobre desenvolvimento.

Registra-se que, por questões éticas, o nome de identificação dos entrevistados foi expresso pela letra inicial. As entrevistas foram realizadas entre junho de 2017 e agosto de 2017, de forma dialogal, e o pesquisador anotava, em caderno de campo, todas as falas. Para evitar possíveis constrangimentos, a sistematização das informações ocorreu posteriormente, no formato de relato de campo.

As estratégias de coleta e sistematização de dados foram distintas, mas complementares, por permitirem uma leitura dos documentos oficiais e das disputas políticas do município. Esse material foi indispensável para selecionar as pessoas que poderiam reconstituir, por meio de suas lembranças, de que modo as relações político-econômicas-socioculturais se estabeleceram e quem foram os indivíduos desprivilegiados na constituição do desenvolvimento.

A proposta, conforme anunciada, foi a de confrontar os documentos que registram a história oficial, com as falas dos indivíduos que estiveram à margem do processo de desenvolvimento de Itajubá. Sobre a situação socioeconômica destes indivíduos, o trabalho de Andrade e Ferreira (2013) revela que, na microrregião de Itajubá, 36,80\% do contingente demográfico encontra-se abaixo da linha da pobreza, sendo, especificamente no município de Itajubá, 19,3\%; número elevado em comparação com os demais municípios do sul de Minas Gerais. ${ }^{4}$

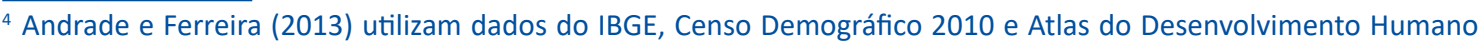
no Brasil 2003.
} 
Na análise dos dados levou-se em conta a visão de um determinado grupo de indivíduos para se compreender o coletivo. Em termos explicativos, busca-se promover uma articulação entre pergunta-problema, dados coletados e um campo simbólico de disputas travadas ao longo da construção do que se denomina desenvolvimento, sem perder de vista as relações de poder implicadas. A aposta está na trajetória de análise proposta por Bourdieu et al. (1997), descrita no capítulo "Compreender" do livro A Miséria do Mundo.

Nas sobreposições das falas e dos documentos, vislumbram-se as dimensões simbólicas presentes nas relações conflituosas estudadas, um campo de forças e de disputas sociais, culturais, econômicas, normativas e que compõe um conjunto de práticas, o que o autor chama de habitus. Estes manifestam-se por meio de imposições de arbitrários culturais, chamados de "violência simbólica".

Diante da perspectiva apontada, as entrevistas privilegiaram por dar voz e vida aos relatos dos entrevistados, no sentido de valorização das suas experiências, as quais trouxeram elementos para reflexão a partir das noções de noção de "campo" e de "dissimetria social" de Bourdieu et al. (1997, p. 695). Por meio dessas noções emergiram os discursos hegemônicos, as rupturas, as resistências e as dimensões socioculturais dos processos de desenvolvimento desencadeados.

Acrescenta-se às apropriações de Pierre Bourdieu, do ponto de vista teórico, as referências de cultura postas por Willians (1992), e de táticas e estratégias pensadas por Certeau (1994), pertinentes para corroborar no conjunto das análises aqui propostas, o que será articulado no decorrer da reflexão.

Nessas disposições conceituais, não se perde de vista as concepções de desenvolvimento elaboradas em Pimenta (2014), as quais são apropriadas para organizar a correlação entre desenvolvimento e cultura e desvincular o conceito de desenvolvimento do mero crescimento econômico. Não se perde ainda as concepções de lanni (1992), quando demonstra como o desenvolvimento brasileiro seguiu dentro de uma lógica desigual e combinada, que favoreceu os detentores do poder econômico, mas gerou problemas estruturais que permanecem na atualidade.

Partindo desses lugares conceituais e teóricos, este estudo propõe a reflexão sobre políticas de desenvolvimento adequadas às realidades locais ao invés de se replicar modelos prontos.

Este artigo estrutura-se da seguinte forma: a primeira seção traz uma descrição de Itajubá e aspectos que a caracterizam, os quais dialogam com as proposições exaradas. A segunda seção dá ênfase às dimensões subjetivas, às falas e impressões dos itajubenses sobre o local e suas táticas de inserção socioeconômicas. A terceira seção apresenta as estratégias de poder local para pôr em prática as configurações de desenvolvimento ali pensadas. Os dados empíricos e os referenciais teóricos aparecem em toda a extensão textual. Por fim constrói-se as considerações finais e apresenta-se as referência bibliográficas empregadas na pesquisa.

\section{DESCRIÇÃO DO LOCAL: Impressões e Caracterizações Econômicas e Demográficas}

A microrregião de Itajubá está situada na mesorregião do Sul de Minas Gerais. O município possui população estimada, em 2017, de 97.000 habitantes em uma área de $2.979 \mathrm{Km}^{2}$, destes 82.761 situados na zona urbana e 7.896 na rural. ${ }^{5}$ A microrregião

\footnotetext{
${ }^{5}$ Informações retiradas do site IBGE cidades. Disponível em: http://cidades.ibge.gov.br/xtras/temas.php?lang=\&codmun=313240\&idtema=1\&search=minas-gerais |itajuba |censo-demografico-2010:-sinopse-. Acesso em: 12 set. 2017.
} 
é composta por 13 municípios: Brasópolis, Consolação, Cristina, Delfim Moreira, Dom Viçoso, Itajubá, Maria da Fé, Marmelópolis, Paraisópolis, Piranguinho, Piranguçu, Virgínia e Wenceslau Braz. O município apresenta um IDHM satisfatório em relação ao país: $0,787 .{ }^{6}$ Trata-se de um município de médio porte, com a maior área urbana da microrregião - 290,4 $\mathrm{Km}^{2}$-, gerando emprego e renda para os demais municípios menores.

Quanto à localização geográfica, está situada na Serra da Mantiqueira, com relativa proximidade ao Vale do Paraíba Paulista, cerca de 90.9 Km da BR 459 e da MG 350, configurando-se como fluxo de mercadorias do Sudeste brasileiro pela rodovia federal BR 459, que, por sua vez, se liga a duas das principais rodovias do país: a Fernão Dias e a Presidente Dutra. A microrregião compõe a mesorregião do Sul de Minas Gerais, que se encontra relativamente próxima ao eixo Rio de Janeiro-São Paulo, conforme se vê no mapa a seguir (Figura 1), configurando-se como importante polo de desenvolvimento no Estado de Minas Gerais (PIMENTA, 2014).

Figura 1 - Mapa da Microrregiões do Sul de Minas Gerais

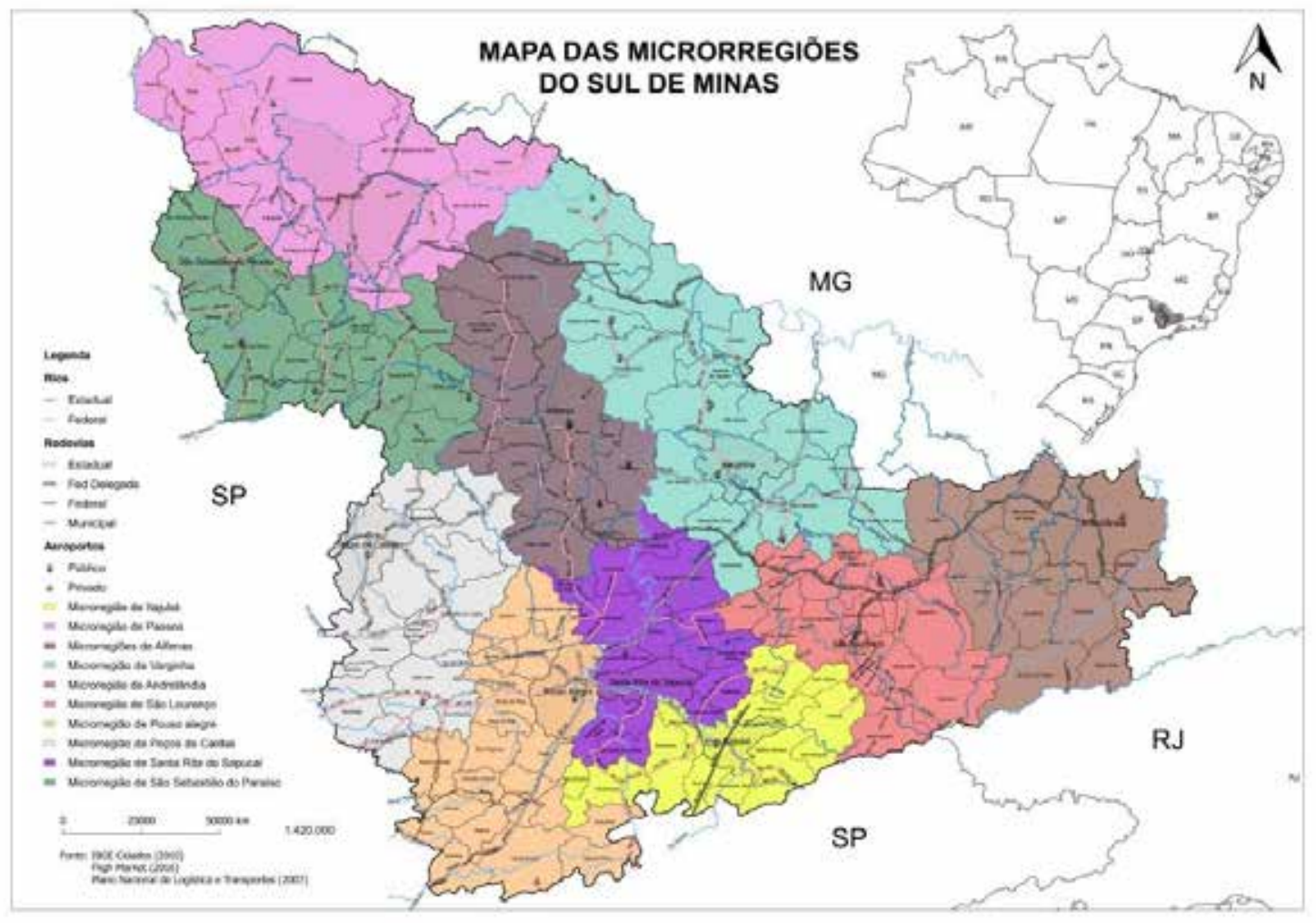

Fonte: Elaborado pelo Núcleo de Estudos Interdisciplinares Sobre Desenvolvimento (NEID) da Universidade Federal de Itajubá.

Ao percorrer Itajubá podemos observar mudanças em seu cenário urbano. A região central é marcada por praças arborizadas, com destaque para a Praça Theodomiro Santiago, próxima à Igreja Matriz Nossa Senhora de Soledade, local da fundada em 1891.

\footnotetext{
${ }_{6}^{6}$ Dados do IBGE. Disponível em: https://cidades.ibge.gov.br/v4/brasil/mg/itajuba/panorama. Acesso em: 16 set. 2017.
} 
Na praça observam-se jardins repletos de flores importadas que não compõem as espécies nativas da região, com um tipo de palco feito de alvenaria, onde, rotineiramente, ocorrem apresentações artísticas, e uma fonte que jorra água iluminada com luzes coloridas vistas durante a noite.

A área central é composta por edifícios comerciais e alguns prédios históricos que remetem à arquitetura colonial e que são sedes de estabelecimentos públicos e privados de renome, dentre os quais se destacam: o Palácio 26 de Fevereiro, a Casa Rosa, o Grande Hotel Itajubá, o Clube Itajubense e a Escola Estadual Coronel Carneiro Júnior.

As pessoas que transitam pelo centro são de diversas idades e características físicas. Alunos passam vestindo uniforme escolar, trabalhadores do comércio e da prefeitura, policiais militares e da Guarda Municipal identificam as instituições a que estão vinculados por suas vestimentas.

Rotineiramente, o centro da cidade é movimentado. Em fins de semana observam-se feiras de artesanato local e hippies que confeccionam e vendem seus artefatos. Nestes artefatos percebe-se a confluência do rural e do urbano, que parece marcar as relações ali presentes. Em um mesmo espaço veem-se produtos do campo, como mel e derivados, roscas caseiras, doces regionais e bolos. Também se encontram produtos com características urbanas, como roupas para animais de estimação, enfeites para residências, adornos, como brincos, colares, pulseiras, e confecções de crochê e tricô.

Em feriados e datas comemorativas ocorrem paradas, desfiles, bandas locais tocam suas músicas e artistas apresentam seus trabalhos ao ar livre. A presença de ambulantes e vendedores em geral é constante. Em todos estes eventos nota-se a presença das autoridades policiais e a preocupação do poder público com a segurança e com a imagem de cidade organizada.

O comércio local caracteriza-se pela alimentação: sorveterias, venda de açaí, lanchonetes, bares e restaurantes. Existem lojas de roupas e brinquedos que datam dos anos 70, ou anteriores, pertencentes a libaneses e descendentes que imigraram para Itajubá e, até a atualidade, ocupam-se do comércio. Na fala dos itajubenses repete-se a informação de que, ao contrário dos nativos da região, estes imigrantes produziram laços de solidariedade profundos entre si e, com isso, conseguiram se estabelecer economicamente em uma cultura diferente.

Também se percebem barracas e lojas de artigos importados, com camelôs e ambulantes que se utilizam da informalidade para se inserir na economia. Dentre estas pessoas, observam-se migrantes da Região Nordeste do Brasil.

Os itajubenses nativos são mais presentes em empregos formais. Estes afirmam que "os turcos7 mandam na cidade, controlam o comércio, tudo é controlado por eles [...] estes tempos atrás, iam fazer uma feira com roupas de São Paulo, os turcos não deixaram" (“M. J.").

Ouvem-se relatos de assaltos e pequenos furtos a lojas ou pessoas nas ruas, que são esporádicos e não ocorrem constantemente. Em um programa semanal de rádio local, as autoridades relatam as ocorrências de crimes. Nos últimos meses vêm alertando

Embora sejam de origem síria e libanesa, a população reconhece estes indivíduos como turcos. 
a população quanto ao aumento da criminalidade de casos de homicídio. Em contrapartida, a fala de uma gestora pública entrevistada mostra que Itajubá possui um dos menores índices de criminalidade, em comparação com a realidade brasileira.

Às terças-feiras, sábados e domingos, são organizadas feiras, nas quais vendem-se produtos agrícolas, parte destes oriundos da produção de moradores das áreas rurais da microrregião. Também se observam atravessadores, vendedores de pastéis, bolos, doces, mel, café, frangos, leitoas, queijos, etc., que disputam seus espaços com outros produtos, como artigos eletrônicos, roupas, CDs e DVDs não autênticos.

Fato curioso é que as feiras de sábado e terça-feira ocorrem em ruas centrais, fechadas exclusivamente para este fim, no período entre $5 \mathrm{~h}$ e $13 \mathrm{~h}$. A feira de domingo ocorre na Ceasa, local de compra e venda de produtos agrícolas no atacado.

Esta informação demonstra como a ruralidade está presente nas relações ali estabelecidas e como a noção de espaço simbólico em disputa parece ser um misto entre rural e urbano, moderno e tradicional, simultaneamente.

Mesmo com esse aspecto, seus habitantes conhecem Itajubá como "cidade universitária". Além de ser sede da Universidade Federal de Itajubá, possui outras instituições de Ensino Superior privadas, como o Centro Universitário de Itajubá - Fepi -, a Faculdade de Ciências Sociais Aplicadas do Sul de Minas - Facesm -, a Faculdade de Enfermagem Wenceslau Braz e a Faculdade de Medicina de Itajubá, dentre outras instituições.

Este fator também interfere na organização da cidade, uma vez que muitas residências foram transformadas em repúblicas de estudantes e são alugadas aos alunos durante o período letivo. Como consequência, percebe-se uma forte especulação imobiliária e o encarecimento de residências e terrenos.

Itajubá recepciona indústrias locais e multinacionais que empregam habitantes de toda a microrregião, como a Mahle, General Elétric, Balteau, Helibrás, Imbel, Higident, Sisvôo, dentre outras.

De acordo com os dados do IBGE (2017), as atividades econômicas urbanas organizam-se da seguinte forma: fabricação de peças e acessórios para automóveis (10\%); administração pública em geral $(6,7 \%)$; educação superior (5,3\%); atendimento hospitalar (4\%); fabricação de armas de fogo e munição (3,5\%); supermercados $(3,2 \%)$; fabricação de detergentes e sintéticos (3,2\%); abate de reses (3,1\%); restaurantes (3\%); fabricação de aeronaves (2,5\%); fabricação de fios, cabos e condutores eletrônicos isolados $(2,1 \%)$.

Os números não são capazes de capturar as reais relações ali estabelecidas. Embora a população urbana seja maioria, alguns costumes rurais são nitidamente percebidos nas falas, nos hábitos e na organização da cidade. Por exemplo, as já mencionadas feiras locais, os produtos vendidos no mercado municipal, como queijos e doces produzidos nas localidades rurais, o hábito de ter uma horta no quintal de casa ou criar galinhas. 0 modo e o estilo rural de vida estão presentes nas relações e laços locais.

\section{DIMENSÕES SUBJETIVAS: Táticas}

A leitura de lanni (1992) propõe a compreensão dos meandros do desenvolvimento a partir da leitura do passado e das circunstâncias históricas. Da mesma forma, buscou-se, nos documentos e falas dos indivíduos que compõem a história de Itajubá, esta perspectiva. 
Certeau (1994) refere-se ao homem que detém o domínio da cultura de homem ordinário, aquele que se utiliza de estratégias que Ihe garantem a dominação de uma sociedade, na qual a linguagem se configura como elemento central para tal dominação. Por outro lado, o homem "vencido" também se apoia na cultura e em táticas para se defender da ordem estabelecida (CERTEAU, 1994).

No intuito de problematizar as informações contidas nos documentos oficiais, propôs-se capturar as falas dos indivíduos que estiveram à margem do sistema produtivo e criaram táticas para superar as estratégias da ordem dominante (CERTEAU, 1994). As dicotomias, moderno versus tradicional, rural versus urbano, estão inscritas nestas relações.

Como o modo de produção industrial hegemônico não permite o acesso de todos os indivíduos de forma equânime aos bens e serviços disponíveis, a cultura possibilita a coexistência de estratégias, que são mecanismos utilizados por aqueles que detêm o modo de produção. Na apropriação dos argumentos de Certeau (1994), adaptado à realidade histórica estudada, as estratégias de desenvolvimento ficam a cargo dos detentores dos meios de produção. Por outro lado, indivíduos, grupos denominados de minoritários e pessoas às margens, estabelecem táticas de sobrevivência. Nesse sentido, o silêncio, a passividade, a subserviência, a aceitação ou a resistência e as lutas sociais, são formas de táticas.

As táticas utilizadas por aquelas pessoas que estão à margem do processo de inserção social pelas portas da frente, estão inseridas como meios para superar dois elementos latentes: a burocratização do trabalho, ligada à necessidade de especialização, e o acesso à propriedade privada.

Com relação ao campo do trabalho, duas questões são evidentes nas falas: (1) o trabalho rural, com destaque para a produção agrícola de fumo, milho, café e banana, com o que os pequenos produtores sobrevivem; (2) as dificuldades de inserção no mundo do trabalho urbano em razão das exigências de qualificação, mesmo que mínimas.

$\mathrm{Na}$ análise das atas do Legislativo, datadas da primeira metade do século $20,{ }^{8}$ percebe-se o uso repetitivo da palavra progresso nas falas dos agentes públicos, indicando o esforço da administração em conferir à região uma ideia de desenvolvimento ligada ao crescimento e incremento do urbano em detrimento ao rural.

A concepção de desenvolvimento, presente nas falas e ações dos agentes públicos, aproxima-se de um viés positivo de sociedade que visa o progresso como fim a ser alcançado. A preocupação maior é com a faceta econômica, alinhada à ideia shumpeteriana de que o empresário inovador é o responsável por alavancar o "fluxo circular" e, então, desencadear o desenvolvimento (SHUMPETER, 1997).

A resistência do rural se dá por outra via: a da cultura e da tradição. O comércio de produtos agropecuários, o uso de charretes e carroças, além da presença de animais no cotidiano dos itajubenses, são elementos que aparecem e permanecem na história de Itajubá e em seu desenvolvimento.

\footnotetext{
3 Foram analisadas atas de reuniões dos vereadores da Câmara Municipal da cidade de Itajubá no período de 1920 a 1950.
} 
Em virtude da amplitude do termo cultura, apropria-se aqui do conceito posto por Raymond Willians (1992), no qual a cultura se estabelece com todo modo de vida de uma sociedade. Este autor a compreende como sistema de significações e meio para estudar as relações consideradas verdadeiras, mas que podem exprimir uma realidade diferente na prática, como "uma dada ordem social é comunicada, reproduzida, vivenciada e estudada" (p. 13). Na concepção desse autor, ver a cultura implica ver a sociedade.

O trabalho de Willians (1992) nos dá indícios de que podem existir formas alternativas e contestadoras presentes nos saberes locais que fazem frente às formas instituídas. No local encontram-se as condições para processos econômicos, socioculturais, políticos e de sociabilidade, distintos da lógica da competição, da disputa e da cultura individualista vigente nas relações urbanas.

No que se refere às relações de trabalho, a Câmara Municipal regulamentou, nos anos 30, a profissão de mestre de obra, que obrigava todos que trabalhavam em construção civil a se submeterem a uma prova com questões de língua portuguesa, matemática e conhecimentos específicos para que recebessem um certificado que thes permitissem atuar na profissão, sem o qual não poderiam exercer sua função.

Este fator parece ser mais excludente que propriamente organizador, levando em conta as dificuldades de acesso à educação para os trabalhadores que já se ocupavam da função. Dentro desta lógica, os cidadãos, trabalhando no campo ou na cidade, muniram-se de táticas para superar os entraves e garantir as condições de sobrevivência econômica.

No meio rural percebeu-se vasta disponibilidade de oferta de trabalho nas grandes propriedades. "B", 93 anos, trabalhou do final da década de 30 até quando seu corpo suportou, por volta dos 85 anos. Adotou uma tática comum entre os trabalhadores rurais da região: plantava em sua propriedade, que herdou dos pais, e, ao mesmo tempo, trabalhava para fazendas maiores. Desta forma, conseguiu dedicar-se mais às atividades em sua propriedade.

$\mathrm{Na}$ condição de morador da zona rural, vendia seus produtos nas feiras organizadas na cidade: "não perdia uma feira, fazia chuva ou sol", comentou sobre as idas à feira com a bagageira ${ }^{9}$ cheia para comercializar suas bananas.

Os indivíduos oriundos do campo eram vistos como despreparados e incapazes para a racionalidade que se buscava ao longo da primeira metade do século 20 . Eram dispensados do serviço militar aqueles que vinham da zona rural. Sabendo disso, muitos se passavam por lavradores para se evadir da obrigação com o Exército Brasileiro.

[...] era comum, no meu tempo, virem pessoas estudadas, de posse, com roupas simples e quando o Sargento perguntava o que faz? Ele respondia: - Sou lavrador! Então era dispensado (“D”).

Esta informação denota uma presença intencional de aspectos racionais que circunscreveram o imaginário social de Itajubá em seu processo de desenvolvimento. Desta forma, o rural e o tradicional mantiveram-se mediante as permissões, restrições, desorganizações e reorganizações que se dão no campo da cultura.

${ }^{9}$ Veículo de carga tracionado por cavalo ou burro, semelhante a uma carroça. 
No urbano também se observou dimensões específicas. Outro entrevistado - "M" sempre morou na zona urbana e muniu-se de outras táticas para ter acesso aos benefícios do desenvolvimento. " $M$ " não se adaptou ou não encontrou oferta de trabalho formal. Via-se como um artista e passou a trabalhar com sua vocação para se sustentar. Pintava faixas, letreiros e anúncios em tela, madeira e metal, e sempre trabalhou em sua própria casa.

Passou por dificuldades quando empresas da região começaram a fazer trabalho gráfico com uso de máquinas e por um preço mais baixo. "Passei momentos difíceis; aí tive que me atualizar" ("M"). Ao longo dos anos 2000, procurou aprofundar-se nos conhecimentos sobre os recursos da informática e adquiriu equipamentos com empréstimo em banco da cidade.

As falas de " $M$ " mostram que nem todos os cidadãos se alinharam às relações formais de trabalho ou dispunham de propriedades na zona rural. Nesse caso, foram forçados a se tornarem indivíduos criativos, adaptáveis e desenvolver táticas para superar os empecilhos impostos pela racionalidade vigente.

A concepção de desenvolvimento é permeada por tendências globais que se evidenciam em hábitos e práticas. O local possui seus mecanismos, que permitem fazer frente ao global. Esses mecanismos podem ser identificados por meio da cultura. Em outros termos, "a cultura se debate entre pressões locais e injunções universais" (CARVALHO, 2013, p. 50).

\section{PROPRIEDADE PRIVADA: Estratégias E Dimensões Estéticas De Urbanização}

As táticas daqueles que estiveram à margem do processo de desenvolvimento, coexistiram com as estratégias do poder público em impor suas concepções de desenvolvimento no imaginário social.

Dentre estas estratégias, a Câmara Municipal formulou um Código de Posturas em 1917, ${ }^{10}$ que estabeleceu critérios de conduta, moradia e regulamentações estéticas, dentre as quais as construções urbanas. Os artigos 48, 62, 63 e 99 do referido Código, proibiam a construção de casas de "meia água, cafuas ou pequenas casas" dentro da zona urbana. Também proibiram os telhados de capim ou palha e muros de taipa, comumente utilizados nas comunidades locais próximas.

A não observação destas regras previa o pagamento de multa e prisão de três dias. Além desta, também eram proibidas construções dentro de quintais, a prática de divisão de casas entre famílias diferentes, habitações coletivas e cortiços, por serem desfavoráveis à "higiene" e "saúde pública" (RIOS, 2015).

\footnotetext{
10 O referido Código de Posturas trazia regulamentações gerais sobre a conduta dos habitantes. Apesar de formulado em 1917, ainda estava em vigor durante o período pesquisado.
} 
Esta visão de mundo era compartilhada pelos jornais que circulavam pela cidade, como "O Sul de Minas" e a "Gazeta de Itajubá", que, por sua vez, periodicamente publicavam notas de incentivo à higiene, hábitos "civilizados" e petições de demolição de cortiços considerados focos de "miasmas", ${ }^{11}$ propícios ao surgimento de epidemias.

Durante as décadas de 50 e 60 os jornais destinaram parte de suas páginas ao ensino de técnicas de higiene, como lavar as mãos antes das refeições, tomar banho todos os dias, lavar os alimentos, não nadar nos rios, etc.

Tal preocupação, entretanto, restringia-se ao centro/sede do município, diferentemente de sua região suburbana, "porque a população que vivia naqueles tipos de habitação fazia parte da população pobre, empregada ou desempregada, na maioria mestiça e sem propriedade" (RIOS, 2015, p. 55).

A ideia de modernidade está contida nestas técnicas e este aspecto conecta a concepção de desenvolvimento atribuída à microrregião de Itajubá. Esta fomenta divisão socioeconômica que se agrava por uma visão de progresso e de modernidade da qual nem todos têm os mesmos benefícios e que se restringe ao crescimento econômico. A noção de crescimento econômico não deve ser confundida com desenvolvimento, ${ }^{12}$ no sentido do termo aplicado a esta pesquisa.

Ao mesmo tempo, diversas fábricas de massas, pertencentes a descendentes de italianos, estabeleceram-se na região e logo passaram a pedir a isenção de impostos à Câmara Municipal pelo período de dez anos. Mediante a comprovação de renda, era concedida facilmente tal petição.

As empresas com capital superior a 200 contos de réis pagariam metade da taxa equivalente ao serviço de abastecimento de água e esgoto. Estas informações apontam para uma facilitação das relações e condições para os detentores do sistema produtivo, a medida que se percebe a burocratização da inserção social e econômica para a população marginalizada.

A apropriação do poder público em benefício próprio é evidente nas falas, leis e ações idealizadas pelos agentes sociais e se aproxima de uma concepção de desenvolvimento desigual e combinado (IANNI, 1992).

Com relação à propriedade privada, há que se levar em consideração a geografia do local. Itajubá é rodeada pelas montanhas da Serra da Mantiqueira e às margens do Rio Sapucaí, que integra a bacia do Rio Grande, localizando-se na Região Sudeste e atravessando dois Estados, São Paulo e Minas Gerais. O Rio Sapucaí nasce na Serra da Mantiqueira, na cidade de Campos do Jordão - SP -, a uma altitude de $1.650 \mathrm{~m}$, e deságua no Lago de Furnas, a 780 m de atitude, atravessando, aproximadamente, 343 km (34 km dentro do Estado de São Paulo e 309 km em Minas Gerais).

\footnotetext{
${ }^{11}$ Emanação proveniente de detritos orgânicos em decomposição, considerada, antes de pesquisas no campo da microbiologia, causadora de doenças e epidemias. Durante o período de pesquisa este termo foi encontrado nos jornais e documentos.

12 Apropria-se do conceito de desenvolvimento elaborado por Pimenta (2014).
} 
Nestes tempos, nos anos com maior intensidade de chuvas, ocorriam alagamentos nas partes baixas e deslizamento de terras nas encostas. Este fator marcou tanto Itajubá que nos jornais da década de 40 a cidade era chamada de "A Veneza sul-mineira", por conta das recorrentes enchentes que assolavam sua população.

Em alguns lugares formavam-se regiões pantanosas, conhecidas, na linguagem local, como "brejo" ou "biquinha". Nas regiões altas prevaleciam grandes propriedades rurais que comprimiam o espaço urbano em formação.

Nas cheias do Sapucaí, desde a década de0930 até a de 60, ocorriam problemas de saúde pública nas diversas localidades habitadas na circunscrição de Itajubá, tais como a proliferação de doenças, como febre e diarreia, agravadas pelo desconhecimento de hábitos de higiene por parte da população.

Evidencia-se que a questão da "grande propriedade privada" tornou-se um entrave para a construção do espaço urbano e o desenvolvimento local. Mediante essa situação, o poder público, representado pela Câmara Municipal de Itajubá, iniciou esforços para repensar a questão da propriedade privada e a construção do espaço, conforme se constata a seguir:

Uma das indicações do vereador José Manso Pereira Cabral, aprovada pela câmara em janeiro de 1894, dá a exata dimensão desse problema [...] Ele propôs a desapropriação por utilidade pública de "partes" de diversos terrenos privados, entre os quais o do próprio presidente da Câmara (RIOS, 2015, p. 26).

Estas informações apontam os caminhos que os detentores da propriedade privada trilharam ao se apropriarem da geografia local, e, em alguns casos, foram forçados a desapropriar suas terras para a construção do local. É evidente também que esta estratégia não se deu de boa vontade ou por conveniência. Havia interesses e acordos econômicos em jogo.

As informações apontadas pelos documentos indicam como os detentores do poder econômico utilizam estratégias (CERTEAU, 1994) para estabelecer ganhos de capital oriundos de questões ligadas aos próprios problemas do local.

Em 1919, como de costume da época, um cidadão enviou uma carta ao jornal local assinada por "X. Y.", sugerindo a demolição de um espaço conhecido por "morro são Benedito" e o aproveitamento das terras do referido morro para o aterramento de um brejo existente nas proximidades, que, na avaliação deste cidadão, resultaria em "ótima área para construções".

Esta informação dá indícios da relação entre a topografia da região e a atribuição de valor a propriedades imobiliárias, formação de um mercado imobiliário especulativo sob o qual se dá a formação do espaço urbano de Itajubá.

A intenção dos agentes públicos locais era modificar a natureza em nome da civilização e do progresso, sem levar em consideração a sustentabilidade ambiental, ${ }^{13}$ conforme propõe Sachs (1986). Desta forma, percebem-se falas dispostas a retificar o Rio

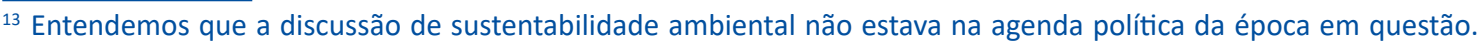
Não somente na microrregião, mas em um contexto geral.
} 
Sapucaí desde o século 19 até setembro de 1957, quando começaram as obras a pedido do deputado Euclides Cintra, por carta direta ao então presidente da República Juscelino Kubitscheck (GUIMARÃES, 1987).

Outro aspecto da formação do espaço urbano está atrelado à produção agrícola, com destaque para o escoamento do café e do fumo, principais produtos da microrregião na passagem do século 19 para o 20. Neste período, Itajubá era referência na produção agrícola no âmbito nacional (ANDRADE; FERREIRA, 2013).

Para este escoamento, construiu-se a linha férrea de Itajubá em 1891 (RIOS, 2015), que favoreceu a ampliação do perímetro urbano, de pontos de comércio, transportes de carga e construção civil. Conforme mencionado anteriormente, os fluxos de transporte estão ligados a modificações étnicas da cidade, em que se destaca a imigração europeia naquele contexto.

De acordo com Rios (2015), a construção da linha férrea desconsiderou a organização do espaço urbano ali presente. Este fato forçou a redistribuição do traçado urbano já existente e trouxe consequências para o desenvolvimento urbano futuro. Percebe-se estas consequências nos muitos atos de desapropriação de terras privadas para fins públicos, construção de ruas, praças, organização da cidade e em obras de aterramento em regiões alagadas próximas à ferrovia.

Conforme observado, os processos de desenvolvimento de Itajubá não levaram em consideração as demandas locais, sejam elas sociais, culturais ou ambientais. Ainda assim, os indivíduos viram na cultura uma saída para se sustentar e se inserir.

\section{CONSIDERAÇÕES FINAIS}

As configurações socioculturais da cidade de Itajubá revelam um local com forte tradição rural e costumes peculiares que se evidenciam nas falas, nas práticas e nas relações ali observadas.

O desenvolvimento da cidade não trilhou, do ponto de vista histórico, caminhos próprios, estes pautados em suas demandas e particularidades. Pelo contrário, privilegiou a inserção de um modelo de sociedade regrado na racionalidade moderna industrial, na propriedade privada e nas lógicas da burocratização das organizações e do trabalho formal.

A cultura, entretanto, foi um escape àqueles que não dispunham dos meios de produção. Por meio dela, elaboraram táticas que se evidenciam em saberes e fazeres específicos, percebidos tanto no rural quanto no urbano, capazes de superar as estratégias dominantes.

A coexistência de instituições racionais (universidades e indústrias) e dimensões da tradição e da cultura local, confere relações sociais únicas que se configuram como objeto de estudo complexo, com demandas ainda não superadas que possuem raízes históricas não percebidas pelas políticas de desenvolvimento vigentes.

A coexistência do tradicional e do moderno também é uma concessão da cultura, que se reinscreve a cada dia como uma colagem mosaica, mas que possibilita outros modos de inserção que permitem pensar outros desenvolvimentos. 
O fato de a cidade se alinhar a um determinado modelo de desenvolvimento pensado no plano nacional, inviabilizou uma série de questões próprias do local e impôs aos indivíduos uma racionalidade a que nem sempre estão aptos a adaptar-se. Nesse caso, aprendem táticas para superação e inserção no contexto coletivo e individual.

As modificações sociais ocorrem dentro de um contexto cultural específico, permeadas por tensões, entraves, convenções e mediações que ocorrem de grupo para grupo, de indivíduo para grupo, de grupo para indivíduo, de instituição para grupos e/ ou indivíduos.

Os esforços desta pesquisa revelaram que o processo de desenvolvimento de Itajubá, MG, construiu um imaginário social de individualização das frustrações. Um processo em que o indivíduo se sente como único responsável pelos fracassos e dificuldades de inserção econômica.

Os sujeitos não se percebem como parte principal da sociedade e sim como alguém de fora, cujas demandas se afastam das demandas destas. Ao mesmo o tempo, os detentores do poder político e econômico se veem como condutores dos demais, como agentes capazes de contagiar o coletivo com suas visões e ideologias.

Mesmo diante destas configurações, a cidade é vista como um lugar acolhedor e existem ilhas de solidariedade que marcam profundamente o imaginário de sua população.

A dicotomia rural e urbana revelou-se um entreposto, um lugar em que elementos de ambos se misturam e tornam-se indissociáveis. Estes elementos são evidentes nas falas, no sotaque, nos costumes e hábitos experimentados em Itajubá.

Os aspectos que juntam os indivíduos que compõem a sociedade itajubense passam pela esfera do trabalho, seja ele rural ou urbano. Neste campo, aparecem elementos de socialização e normatizações, mas, também, colaborações e sociabilidades que são percebidas nas falas e ações empreendidas no local.

\section{AGRADECIMENTO}

À Fundação de Amparo à Pesquisa no Estado de Minas Gerais (Fapemig), pelo apoio.

\section{REFERÊNCIAS}

ANDRADE, Alexandre Carvalho de; FERREIRA, Enéas Rente. Produção familiar, conservação ambiental e turismo no espaço rural da microrregião de Itajubá, Minas Gerais. In: Campo-Território: Revista de Geografia Agrária, v. 8, n. 16, p. 315-341, ago. 2013.

BOURDIEU, Pierre et al. Compreender. In: BOURDIEU, Pierre et al. A miséria do mundo. 17. ed. Petrópolis, RJ: Vozes, 1997. p. 693-732.

CARVALHO, Edgard de Assis. Cultura e complexidade: um trajeto antropológico. In: MELLO, Adilson da Silva; PIMENTA, Carlos Alberto Máximo. Encruzilhadas da cultura: desenvolvimento, tecnologias e sociedade. Taubaté: Cabral, 2013.

CERTEAU, Michel de. Um lugar comum: a linguagem ordinária. In: CERTEAU, Michel de. A invenção do cotidiano. Petrópolis: Vozes, 1994. p. 59-106.

GINZBURG, Carlo. Mitos, emblemas e sinais: morfologia e história. São Paulo: Companhia das Letras, 1989.

GUIMARÃES, Armelim. Itajubá e sua história. Itajubá: Gráfica o Sul de Minas, 1998.

GUIMARÃES, Armelim. História de Itajubá. Belo Horizonte: Imprensa Oficial, 1987.

IANNI, Octávio. A ideia de Brasil moderno. São Paulo: Brasiliense, 1992. 
IBGE. Instituto Brasileiro de Geografia e Estatística. Dados. 2017.

PIMENTA, C. A. M. Projeto: indicativos de desenvolvimento do município de Itajubá, MG: investimentos públicos e privados. 2014. Trabalho (Pós-Graduação) - Universidade Federal de Itajubá, Programa de Pós-Graduação, Desenvolvimento, Tecnologias e Sociedade, 2014. (Fapemig Universal no CSA-APQ 02967-14). PIMENTA, C. A. M. Tendências do desenvolvimento: elementos para reflexão sobre as dimensões sociais na contemporaneidade. Revista Brasileira de Gestão e Desenvolvimento Regional, Taubaté, SP, Unitau, v. 10, n. 3 (número especial), p. 44-66, set. 2014.

PIZARRO, Aloysio. Nossa História... Nossa Tradição... Cronologia de uma Escola de Engenharia que virou Universidade. 1 ed. Itajubá: Papercrome, 2002. 318p.

RIOS, Wilson de Oliveira. Cidade de Itajubá: Câmara Municipal e Desenvolvimento Urbano (1892-1930). Itajubá, 2015.

SACHS, Ignacy. Desenvolvimento includente, sustentável e sustentado. São Paulo: Garamond, 1986.

SCHUMPETER, J. A. A teoria do desenvolvimento econômico. São Paulo: Nova Cultural, 1997.

SKIDMORE, Thomas E. Brasil: de Getúlio Vargas a Castelo Branco 1930-1964. 7. ed. Rio de Janeiro: Paz e Terra, 1982.

WILLIANS, Raymond. 1921-1988 Cultura. Rio de Janeiro: Paz e Terra, 1992. 